\title{
The Production of TiAl by Foundry Processes
}

\author{
Joaquim Barbosa $^{1}$, C. Silva Ribeiro ${ }^{2}$, Caetano Monteiro ${ }^{1}$ \\ ${ }^{1}$ Universidade do Minho, Departamento de Engenharia Mecânica, Guimarães, Portugal \\ Tel: +351 253510220, Fax: +351253516007 \\ ${ }^{2}$ FEUP, Departamento de Engenharia Metalúrgica e Materiais, Porto, Portugal \\ Tel: +351 222041786, Fax: +351222041792
}

Keywords: TiAl, induction melting, crucible

\begin{abstract}
This paper describes a foundry technique that enables the production of TiAl employing an adapted melting procedure that uses an induction furnace with suitable refractory crucibles, inside a controlled atmosphere chamber. The developed technique allows the production of samples with a low and controlled amount of residual elements, with a thin superficial hard skin - known as "alpha-case" - and allows the use of higher superheating temperatures, when compared with alternative melting procedures.
\end{abstract}

The micro-hardness and the residual contamination profiles, from the outside to the interior of samples, are presented and correlated to crucible refractory material and foundry practice.

\section{Introduction}

The use of a ceramic crucible to melt titanium alloys by the induction melting process might be a possible solution both to decrease melting costs (due to energy costs saving) and to eliminate casting defects, such as misrun (due to poor superheating), which are the two important drawbacks of the concurrent melting processes [1,2,3]. However, the high reactivity of titanium alloys may impair the quality of the castings made using crucible induction melting, due to reactions between the melt and the ceramic materials present both in the crucible and in the mould. These reactions may contaminate the castings, due to the absorption of some residual elements, chemical heterogeneities, inclusions and structural variations.

During the melting and solidification/cooling stages, metal-crucible and metal-mould reactions are possible to occur, with a greater probability to the first one, as the metal is at the liquid state and diffusion rates are usually higher. A molten metal-crucible reaction usually results in a uniform increase in the content of residual elements in the metal, due to the stirring effect of the induction field. During solidification the contamination mainly affects the outside region of the specimen, from which results a higher content of contaminant elements near the interface between the casting and the mould wall, continually decreasing to a sort of plateau in which the level of contaminants is held constant (beyond a certain distance from the interface). Refractory materials used to produce foundry moulds are usually single or complex oxides and when a titanium alloy is poured into such moulds, oxygen absorption is usually present, as the mould oxides are less stable than those resulting from the reaction of the melt components with oxygen. This element has a marked tendency to form an interstitial solid solution with titanium. In practice, a superficial layer with 
higher hardness and oxygen content can frequently be found in titanium castings, known as "alpha-case" [4].

Although there are some evident benefits from the use of refractory crucible induction melting when compared to alternative techniques (ISM or VAR) - lower melting costs, lower investment costs, higher superheating, easier operation procedures - this application is still depending on the development of suitable ceramic crucibles, because until now no single material was found to be absolute inert against titanium and titanium alloys.

During the last 3 years, the authors have done some research work on this field. Different kinds of crucibles and ceramic moulds have been evaluated, by pouring TiAl, and results are published elsewhere [5,6]. Among tested ceramic crucibles $-\mathrm{ZrO}_{2}$ stabilized with different materials, $\mathrm{CaO}$ and graphite - only $\mathrm{CaO}$ crucibles revealed to be thermodynamically stable enough to melt TiAl. However, its high higroscopicity and poor thermal shock resistance decrease the possibility to use it on a regular basis. Work done with raw $\mathrm{ZrO}_{2}$ crucibles lead to castings severely contaminated with $\mathrm{Zr}$ and $\mathrm{O}$. From those $\mathrm{ZrO}_{2}$ stabilized with different materials, $\mathrm{CaO}$ stabilized proved to be the best solution. Graphite crucibles revealed to be absolutely useless, due to the high $\mathrm{C}$ content found in the castings.

The main objective of this paper is to describe the results obtained by the use of multi-layer ceramic crucibles to melt TiAl, considering:

- Microhardness and contaminant concentration profiles;

- Correlation between oxygen concentration and microhardness profiles with the "alphacase" extension.

\section{Experimental technique}

A Ti-48Al (at.\%) was used, prepared from commercially pure titanium and aluminium, melted in multi-layer crucibles. To evaluate the effect of a slow cooling rate upon the residual elements content, molten metal was allowed to solidify and cool inside the crucibles.

\section{Process description}

The whole process - melting and cooling - was performed inside a sealed chamber, were an argon atmosphere was maintained, with the chamber being open only after the sample reached room temperature. The melting procedure was the same as used in previous work, which is mentioned elsewhere $[5,6]$.

\section{Multi-layer crucibles}

In previous work, it was reported that stabilized $\mathrm{ZrO}_{2}$ crucibles were unsuitable to melt $\mathrm{TiAl}$, as the castings appeared to be contaminated with $\mathrm{Zr}$ and $\mathrm{O}$, and revealed a significant extension of "alpha-case" [5,6]. Following that work, new $\mathrm{ZrO}_{2}$ crucibles were tested. To decrease interaction with the molten metal, base crucibles were inside coated with yttria, which is a material thermodynamically more stable than $\mathrm{ZrO}_{2}$, in order to avoid direct contact between the $\mathrm{ZrO}_{2}$ grains 
of the base crucible, and the metal. Three different kinds of $\mathrm{ZrO}_{2}$ crucibles were coated and evaluated: $\mathrm{CaO}, \mathrm{MgO}$ and $\mathrm{Y}_{2} \mathrm{O}_{3}$ stabilized $\mathrm{ZrO}_{2}$.

\section{Experimental results}

$\emptyset 40 \times 25 \mathrm{~mm}$ cylinders have been cast. In order to evaluate the structure, samples were collected from the middle section of them, by cutting the cylinders at half their height, and prepared using traditional metallographic techniques. Phase and chemical composition identification were performed by quantitative EDS analysis with standards of pure $\mathrm{Ti}, \mathrm{Al}$ and $\mathrm{Zr}$, using a JEOL JSM $35 \mathrm{C}$ scanning electron microscope.

The results are summarised in table 1 and figure 1, and all conclusions are based upon them. For comparison results using mono-layer crucibles are also presented.

Table 1 - Vickers hardness and $\mathrm{Zr}$ content of samples melted and cooled in different inside coated $\mathrm{ZrO}_{2}$ crucibles

\begin{tabular}{|c|c|c|c|c|c|c|}
\hline \multirow[t]{2}{*}{ Crucible material } & \multicolumn{2}{|c|}{$\begin{array}{c}\text { Vickers hardness } \\
\text { (average) }\end{array}$} & \multicolumn{2}{|c|}{$\begin{array}{c}\text { Zr (\% at) } \\
\text { (surface of sample) }\end{array}$} & \multicolumn{2}{|c|}{$\begin{array}{c}\mathrm{Zr}(\% \text { at) } \\
\text { (inside the sample) }\end{array}$} \\
\hline & $\alpha_{2}+\gamma$ & $\gamma$ & $\alpha_{2}+\gamma$ & $\gamma$ & $\alpha_{2}+\gamma$ & $\gamma$ \\
\hline $\mathrm{ZrO}_{2} / \mathrm{Y}_{2} \mathrm{O}_{3}$ & 303 & 296 & $<0,1$ & $<0,1$ & $<0,1$ & $<0,1$ \\
\hline $\mathrm{ZrO}_{2} / \mathrm{CaO}$ & 306 & 299 & $<0,1$ & $<0,1$ & $<0,1$ & $<0,1$ \\
\hline $\mathrm{ZrO}_{2} / \mathrm{MgO}$ & 306 & 296 & $<0,1$ & $<0,1$ & $<0,1$ & $<0,1$ \\
\hline
\end{tabular}

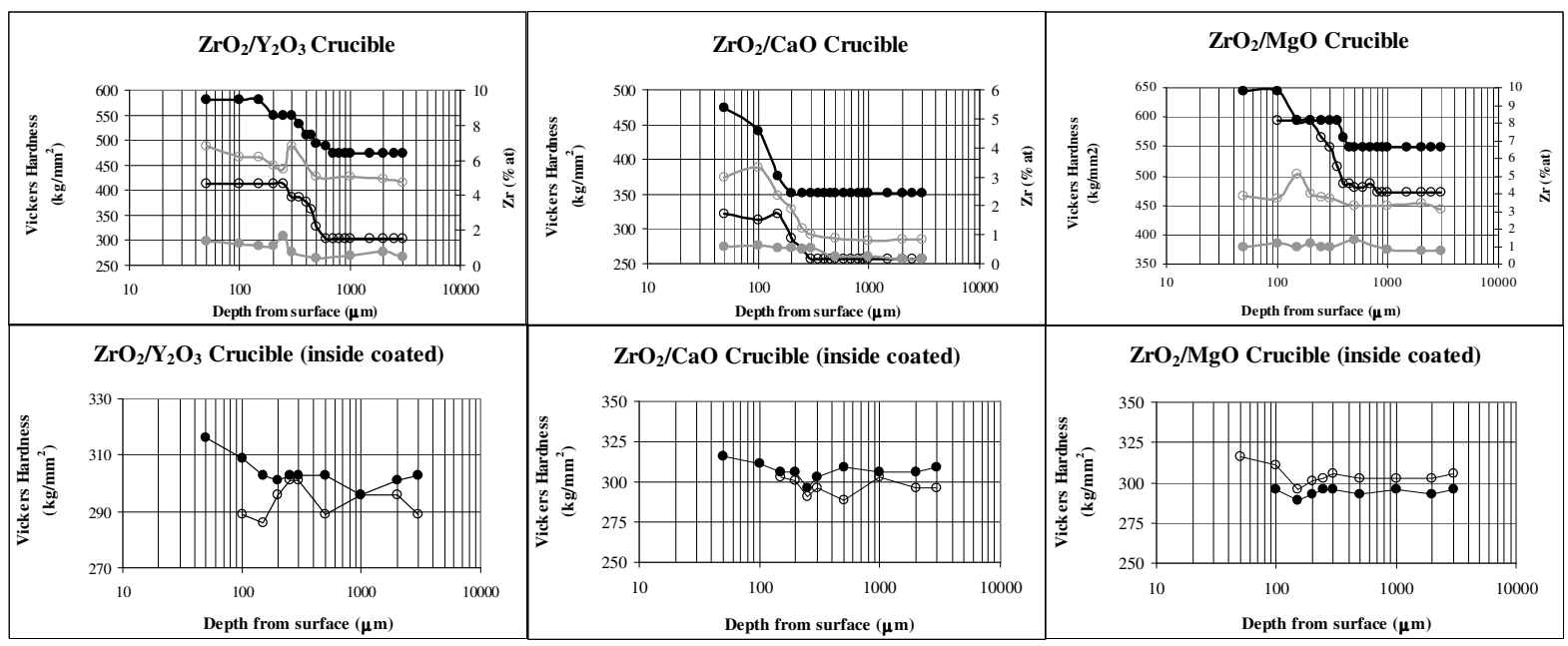

$\begin{array}{llll}\rightarrow & \mathrm{HV} \text { (Dendritic constituent) } & - & \text { - Z Zr (Dendritic constituent) } \\ & -\mathrm{HV} \text { (Interdendritic constituent) } & - & \% \mathrm{Zr} \text { (Interdendritic constituent) }\end{array}$

Figure 1 - Microhardness and $\mathrm{Zr}$ profiles in samples obtained in stabilized $\mathrm{ZrO}_{2}$ and $\mathrm{ZrO}_{2}$ based multi-layer crucibles 
Samples melted and cooled in multi-layer $\mathrm{ZrO}_{2}+\mathrm{Y}_{2} \mathrm{O}_{3}$ crucibles didn't show any contamination with $\mathrm{Zr}$ or any other residual element, what confirms their high stability. Microhardness value is in practice constant throughout the sample (between 296 and $306 \mathrm{HV}$ ), and "alpha-case" was not detected. Microhardness value is similar to that found by authors in samples processed in $\mathrm{CaO}$ crucibles, in previous work [5,6], and it is in accordance with other references for TiAl [7], what might indicate the absence of significant contents of other kind of non-evaluated residual elements, as, for instance, oxygen.

The as cast microstructure of samples, is similar to those found for as cast Ti-48Al melted using other kind of crucibles [5,6]. It contains two microconstituents: a lamellar one with a dendritic pattern revealing two phases $\left(\alpha_{2}+\gamma\right)$, and an interdendritic $\gamma$ phase. Although, in samples obtained in multi-layer crucibles, the volume fraction of interdendritic $\gamma$ is smaller than that found in samples previously obtained in similar single-layer crucibles. This is due to the absence of residual $\mathrm{Zr}$ in the $\gamma$ phase, which was found to stabilize that phase [8].

Every sample revealed the presence of small non-metallic particles at the metal-crucible interface, that were identified as $\mathrm{Y}_{2} \mathrm{O}_{3}$, by XRD. Those yttria particles create a layer, which thickness is about $60 \mu \mathrm{m}$. Their shape and dimensions, are similar to those of the yttria coating, and suggest that some erosion of the coating occurred during melting. Some work is presently being done in order to improve the mechanical resistance of that aggregate.

\section{Conclusions}

1. A multi-layer crucible was produced and employed to induction melt TiAl alloys;

2. These crucibles perform much better than mono-layered $\mathrm{ZrO}_{2}$ crucibles. It was not noticed the formation of the superficial harder and contaminated "alpha-case" layer;

3. The average hardness is constant all over the samples, and it is in accordance with other references for TiAl, melted by alternative procedures;

4. The samples have a $60 \mu \mathrm{m}$ thickness film layer of ceramic particles at the surface, which origin is the inside layer of the crucible.

\section{References}

[1] F. Müller, E. Weingärtner, Metals Handbook, Vol. 15 - Casting, p. 409-410, Ed. ASM, 1989.

[2] D.S. Reed, M.L. Jones, AFS Transactions, 1991, p.697-700.

[3] C. Frueh, D.R. Poirier, M.C. Maguire, R.A. Harding, International Journal of Cast Metals Research, Vol.9, n4, 1996, p.233-240.

[4] T.S. Piwonka, 42Th Annual Technical Meeting of the Investment Casting Institute, publ. Investment Casting Institute, USA, 1994.

[5] J. Barbosa, C. Silva Ribeiro, International Journal of Cast Metals Research, $\mathrm{n}^{\mathrm{o}}$ 12, 2000, p.293-301.

[6] J. Barbosa, C. Silva Ribeiro, Caetano Monteiro, Proceedings do $9^{\circ}$ Encontro da Sociedade Portuguesa de Materiais, Vol.1, 1999, p.129-134.

[7] Materials Properties Handbook - Titanium Alloys, Section VI - Titanium Aluminides, ASM, June 1994.

[8] J.Barbosa, A. Duarte, C. Silva Ribeiro, F. Viana, C. Monteiro, Development in Light Metals Science, Technology and Applications, Key Enginnering Materials, Vol.188, 2000, p.45-54. 